\title{
Evolução dos preços de insumos e valores de mão-de-obra para produção de cana- de-açúcar na região Centro-Sul Tradicional: safra 2014/15
}

\section{Evolution of agricultural inputs prices and labor value for production of sugarcane in the Traditional Center-South region: harvest 2014/15}

\author{
Aline Bigaton ${ }^{*}$; André Felipe Danelon²; Átila Carvalho ${ }^{3}$; Ruan Richard D’Aragone ${ }^{4}$; \\ Haroldo José Torres da Silva ${ }^{5}$, Pedro Valentim Marques ${ }^{6}$
}

\begin{abstract}
1 UNICAMP - Mestranda em Planejamento de Sistemas Energéticos (Faculdade de Engenharia Mecânica) - Rua Alexandre Herculano 120, sala T4, Vila Monteiro - CEP 13418-445 - Piracicaba (SP), Brasil

2 ESALQ/USP, Graduando em Ciências Econômicas - Rua Alexandre Herculano 120, sala T4, Vila Monteiro - CEP 13418445 - Piracicaba (SP), Brasil

${ }^{3}$ ESALQ/USP, Graduando em Engenharia Agronômica - Rua Alexandre Herculano 120, sala T4, Vila Monteiro - CEP 13418445 - Piracicaba (SP), Brasil

${ }^{4}$ ESALQ/USP, Graduando em Administração - Rua Alexandre Herculano 120, sala T4, Vila Monteiro - CEP $13418-445$ Piracicaba (SP), Brasil

${ }^{5}$ ESALQ/USP - Mestrando em Economia Aplicada (Departamento de Economia, Administração e Sociologia) - Rua Alexandre Herculano 120, sala T4, Vila Monteiro - CEP 13418-445 - Piracicaba (SP), Brasil

${ }^{6}$ ESALQ/USP - Professor Titular (Departamento de Economia, Administração e Sociologia) - Av. Pádua Dias 11 - CEP 13418-900 - Piracicaba (SP), Brasil
\end{abstract}

\section{Resumo}

O levantamento de preços de insumos agrícolas - principais produtos utilizados na produção de cana de açúcar - e valor de mão de obra, realizado pelo Programa de Educação Continuada em Economia e Gestão de Empresas - PECEGE, para a safra 2014/2015, evidenciou a importância dos itens analisados na variação dos custos de fornecedores de cana. Apesar da classe de corretivos ter sido a que apresentou maior variação de preços (160\%), foi a classe de fertilizantes que gerou maior impacto nos custos com insumos ( $\mathrm{R} \$ 0,30 /$ ton). Já para o item mão de obra, apesar da variação positiva nos preços ocasionada pelo reajuste salarial, a variação nos custos de produção foi negativa, indicando possível redução de quadro de funcionários em detrimento do aumento de mecanização da lavoura. Para a safra 2015/2016, há expectativa de que a queda dos preços internacionais dos derivados de petróleo amenize os impactos da valorização cambial, a qual tem grande influência nos preços dos insumos, principalmente sobre a classe de fertilizantes.

Palavras-chave: sucroenergético, custos, fornecedores, bioenergia

\begin{abstract}
The research of agricultural input prices - main products used in the production of sugar cane - and labor value, conducted by Programa de Educação Continuada em Economia e Gestão de Empresas - PECEGE, for the 2014/2015 crop, highlighted the importance of the items analyzed in the variation of sugarcane suppliers costs. Despite the class of lime have been presented the highest price variation (160\%), was the class of fertilizers that generated greater impact on input costs ( $R \$$ $0.30 /$ ton). As for the labor item, despite the positive variation in prices caused by the salary increase, the variation in production costs was negative, indicating possible reduction of staff due to of increased mechanization of farming. For the 2015/2016 crop, there is expectation that the fall in international prices of petroleum mitigates the impact of currency appreciation, which has great influence on prices of inputs, especially on the fertilizers class.
\end{abstract}

\footnotetext{
${ }^{1}$ Autor correspondente <alinebigaton@pecege.com>

Enviado: 13 mar. 2015

Aprovado: 29 mar. 2015
} 
Keywords: sucroenergetic, costs, suppliers, bioenergy

\section{Evolução das variações dos preços de insumos e dos valores de mão-de-obra}

Baseando-se no relatório de acompanhamento da safra 2014/2015, em que se encontram os principais indicadores técnicos agrícolas e industriais e os custos de produção de cana-de-açúcar, açúcar, etanol e bioeletricidade no Brasil, realizado anualmente pelo Programa de Educação Continuada em Economia e Gestão de Empresas - PECEGE em parceria com a Confederação da Agricultura e Pecuária do Brasil - CNA, também estão contidos os dados obtidos junto aos fornecedores de cana-de-açúcar. Nesta classificação incluem-se os produtores rurais, técnicos de cooperativas, associações e sindicatos, para os quais são realizados encontros presencias para coleta dos dados, identificação do sistema de produção e aferição dos principais indicadores técnicos e de custos. A pesquisa se divide em três macrorregiões produtoras: Centro-Sul Tradicional (SP e PR), Centro-Sul Expansão (MG, GO, MS e MT) e Nordeste. Para fins de discussão neste artigo, será considerada apenas a macrorregião Centro-Sul Tradicional e com um enfoque apenas em dois fatores de produção: insumos agrícolas e mão-de-obra utilizados no cômputo do custo da cana-de-açúcar de terceiros.

A avaliação da distribuição dos fatores de formação dos custos de produção de cana-de-açúcar é feita sob duas perspectivas, a dos insumos e a dos estágios de produção. Sob a ótica dos insumos é possível segmentar os custos em 6 grupos, a saber, maquinário, insumos, remuneração da terra, mão-de-obra, administrativo e outros ${ }^{2}$. A análise será baseada a partir da perspectiva dos insumos e considerando-se dois agrupamentos: i) insumos agrícolas, composto por diesel, lubrificantes, corretivos, fertilizantes, herbicidas, inseticidas e mudas e ii) mão-de-obra.

$\mathrm{Na}$ distribuição relativa dos fatores de custos de produção de cana-de-açúcar na safra 2014/15 (acompanhamento) sob as perspectivas dos insumos de produção, mão-deobra representa cerca de $8 \%$ e insumos agrícolas $15 \%$. Os custos com insumos agrícolas somados aos de mão-de-obra representaram aproximadamente $30 \%$ do custo total de produção de cana-de-açúcar na região Tradicional (Figura 1), o que demonstra sua representatividade quanto à produção da matéria prima.

2 Outros - Somatório dos fatores: arrendamento, capital de giro, depreciações com benfeitorias e equipamentos de irrigação, remuneração do proprietário e remuneração do capital. 


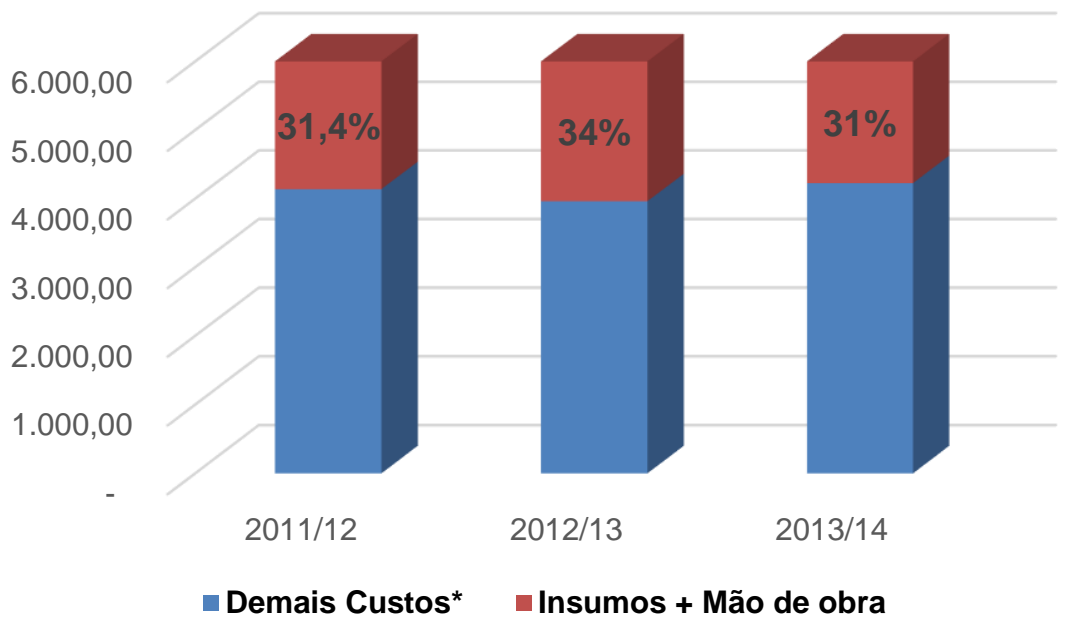

Figura 1. Representatividade dos insumos agrícolas e da mão-de-obra nos custos de produção de cana de açúcar

*Demais custos referem-se aos outros componentes para cálculo do custo total - maquinário, administrativo, remuneração da terra e outros (somatório de arrendamento, capital de giro, depreciação com benfeitorias e equipamentos de irrigação, remuneração do proprietário e remuneração do capital).

O acompanhamento da evolução dos preços dos fatores de produção atrelado a um controle gerencial e um processo de tomada de decisão mais efetivo, proporciona uma melhor gestão de custos. No caso dos insumos agrícolas, por exemplo, o planejamento da época de compra destes produtos, em consonância com a sazonalidade, pode ser um grande diferencial.

Dessa maneira, o PECEGE também realiza o acompanhamento mensal dos preços dos insumos mais expressivos utilizados no processo de produção de cana de açúcar considerando que, a população-objetivo compreende unidades agrícolas setor. Assim, calculam-se sistematicamente um grupo de índices de preços que reflitam a inflação do conjunto de produtos pertencentes ao mercado sucroalcooleiro, especificamente fornecedores de cana-de-açúcar, da região Centro-Sul Tradicional, que está definida pelos Estados de São Paulo e Paraná. Essa região foi dividida em quatro painéis (Catanduva-SP, Piracicaba-SP, Sertãozinho-SP e Porecatu-PR) e a coleta $^{3}$ de dados foi realizada no

\footnotetext{
${ }^{3}$ Alguns preços de corretivos e herbicidas foram coletados junto a Companhia Nacional de Abastecimento - Conab, os preços de óleo Diesel são coletados junto a ANP e preços de mudas
} 
período de maio de 2014 a janeiro de 2015, por meio de ligações e e-mail a produtores de cana-de-açúcar, cooperativas, revendas e fornecedores de insumos, com os quais foram obtidos os preços dos principais insumos utilizados na produção agrícola e o valor da mãode-obra (calculado a partir do salário mínimo de um rurícola).

Os cálculos de variações dos preços foram realizados a partir da ponderação de todos os itens que compõem a cesta de produtos coletados, com base na representatividade de cada item (corretivos, fertilizantes, herbicidas, mão-de-obra, etc) em relação ao valor total gasto com insumos agrícolas e mão-de-obra. O vetor de pesos foi obtido separadamente para cada painel a fim de captar as particularidades de cada região (Ver Anexo B), no entanto as ponderações das quatro mesorregiões, para efeitos de agrupamento, foram definidas a partir dos dados de cana plantada obtidos no SIDRA-IBGE (2015).

$\mathrm{Na}$ equação 1 pode ser observada a metodologia de cálculo que foi utilizada para a obtenção das variações.

$$
I_{j}^{X}=\frac{\sum_{i=1}^{n} W_{i t}\left(R_{i}\right)}{\sum_{i=1}^{n} W_{i t}}
$$

Onde, $I_{j}^{X}$ é a variação de preços do item $j$ para o painel $X ; W_{i t}$ é o peso de cada produto $i$ que conforma um item $j ; R_{i}$ é a variação acumulada do produto $i$ que conforma um item j, ou seja, $R_{i}=\left(\prod_{k=\text { maio } / 2014}^{\text {janeiro } 2015} \frac{P_{i t}}{\text { Pit }-1}\right)-1$.

\section{Discussão}

A Tabela 1 apresenta os preços dos principais insumos agrícolas, segmentados em classes, e para o valor da mão-de-obra. Estes preços estão sem ponderação e são compostos pela média aritmética dos preços coletados com os informantes do projeto.

calculados a partir do preço do ATR junto com os custos de colheita e a produtividade das mesorregiões. 
Tabela 1. Preços dos insumos agrícolas e de mão-de-obra na Região Centro-Sul Tradicional de maio de 2014 a janeiro de 2015

\begin{tabular}{cccccc}
\hline Item & Subitem & Unidade & Mínimo & Médio & Máximo \\
\hline Combustível (Diesel) & Óleo diesel & $\mathrm{R} \$ / \mathrm{I}$ & 2,09 & 2,17 & 2,28 \\
Corretivos & Calcário dolomítico & $\mathrm{R} \$ /$ ton & 45,46 & 91,01 & 120,00 \\
& Gesso & $\mathrm{R} \$ /$ ton & 56,35 & 87,05 & 112,08 \\
& $04-20-20$ & $\mathrm{R} \$ /$ ton & $1.110,45$ & $1.182,80$ & $1.273,33$ \\
Fertilizantes & $05-25-25$ & $\mathrm{R} \$ /$ ton & $1.217,00$ & $1.314,64$ & $1.413,88$ \\
& $05-30-15$ & $\mathrm{R} \$ /$ ton & $1.209,00$ & $1.284,30$ & $1.345,40$ \\
& $18-00-27$ & $\mathrm{R} \$ /$ ton & $1.111,25$ & $1.183,03$ & $1.270,00$ \\
& $20-00-20$ & $\mathrm{R} \$ /$ ton & $1.061,00$ & $1.144,77$ & $1.229,57$ \\
& $28-00-22$ & $\mathrm{R} \$ /$ ton & $1.100,67$ & $1.169,96$ & $1.233,33$ \\
Herbicidas & $2,4 \mathrm{D}$ & $\mathrm{R} \$ / \mathrm{l}$ & 10,75 & 10,96 & 11,20 \\
& Diuron & $\mathrm{R} \$ / \mathrm{Kg}$ & 24,72 & 28,56 & 45,50 \\
& Glifosato & $\mathrm{R} \$ / \mathrm{l}$ & 12,16 & 12,84 & 14,22 \\
& Msma & $\mathrm{R} \$ / \mathrm{l}$ & 13,06 & 14,17 & 14,90 \\
Inseticidas & Plateau & $\mathrm{R} \$ / \mathrm{kg}$ & 436,11 & 445,93 & 456,31 \\
& Tebutiuron & $\mathrm{R} \$ / l$ & 26,73 & 31,28 & 35,02 \\
Lubrificantes & Carbofurano & $\mathrm{R} \$ / \mathrm{kg}$ & 27,42 & 28,11 & 28,69 \\
Mudas & Regent & $\mathrm{R} \$ / \mathrm{kg}$ & 441,53 & 516,10 & 631,86 \\
Mão-de-obra & Cortador de cana (soqueira) & $\mathrm{R} \$ / \mathrm{mês}$ & 770,00 & 830,98 & 900,00 \\
\hline
\end{tabular}

Fonte: Dados da pesquisa

Quanto aos preços de insumos apresentados na Tabela 1, da classe de corretivos, o calcário dolomítico apresentou uma maior amplitude de preços comparativamente ao gesso. Dentre os fertilizantes, um produto que teve destaque quanto às amplitudes foi o 05$25-25$, apresentando quase $R \$ 200,00$ /ton de diferença entre os meses de coleta. Em relação aos herbicidas, os produtos mais utilizados (Glifosato e 2,4 D) não apresentaram grandes diferenças nos preços coletados, entretanto o Diuron obteve variação acima dos 80\%. A menor amplitude foi observada no Carbofurano que manteve o preço estável ao longo do período de coleta.

Na Tabela 2 pode ser observada a variação entre as safras 2012/13 e 2014/15 dos custos de produção dos insumos e mão de obra dos fornecedores, assim como a variação dos preços ${ }^{4}$ no período de coleta do trabalho região Centro-Sul Tradicional.

\footnotetext{
${ }^{4}$ A variação dos preços dos insumos é em relação ao período de maio de 2014 a janeiro de 2015.
} 
Tabela 2. Variações nos preços e nos custos, em percentagem, dos insumos e mão-deobra dos fornecedores de cana-de-açúcar entre as safras 2012/13 e 2014/15

\begin{tabular}{lcccc}
\hline \multicolumn{1}{c}{ Item } & $\begin{array}{c}\text { Variação nos } \\
\text { Preços }\end{array}$ & $\begin{array}{c}\text { Custo na Safra } \\
\mathbf{2 0 1 3 / 1 4}\left(\mathbf{R} \mathbf{\$} / \mathbf{t} \mathbf{1}^{\mathbf{1}}\right.\end{array}$ & $\begin{array}{c}\text { Custo na Safra } \\
\mathbf{2 0 1 4 / 1 5}(\mathbf{R} \mathbf{\$} / \mathbf{t})\end{array}$ & $\begin{array}{c}\mathbf{1} \\
\text { Variação } \\
\text { nos custos }\end{array}$ \\
\hline Corretivos & $18,33 \%$ & 1,25 & 1,47 & $17,57 \%$ \\
Fertilizantes & $11,34 \%$ & 7,45 & 7,75 & $3,97 \%$ \\
Herbicidas & $-1,49 \%$ & 2,21 & 2,44 & $10,59 \%$ \\
Inseticidas & $-11,61 \%$ & 0,72 & 0,76 & $6,20 \%$ \\
Lubrificantes & $17,34 \%$ & 0,15 & 0,17 & $13,38 \%$ \\
Mão de obra & $8,04 \%$ & 8,48 & 6,58 & $-22,37 \%$ \\
Mudas & $12,41 \%$ & 2,05 & 2,26 & $10,36 \%$ \\
Combustível (Diesel) & $4,90 \%$ & 1,48 & 1,68 & $13,38 \%$ \\
\hline
\end{tabular}

Fonte: Dados da pesquisa

Nota: ${ }^{1}$ Variação calculada a partir do custo apurado em reais por tonelada de cana-de-açúcar

Observa-se na Tabela 2 que o item com maior variação nos preços foram os corretivos, com aumento de cerca de 18,33\% no período entre maio de 2014 e janeiro de 2015. Os custos de produção associados à utilização deste insumo aumentaram cerca de $17,57 \%$ entre as safras 2013/2014 e 2014/2015, saltando de $R \$ 1,25$ /tonelada para $R \$$ 1,47/tonelada. A segunda maior variação nos preços foi em relação aos lubrificantes com aumento de $17,34 \%$, no entanto a variação capturada para os custos foi de $13,38 \%$. É importante mencionar que a variação dos custos de produção, grosso modo, pode ser decomposta entre as variações de preços e de quantidades. Por exemplo, embora os preços de um determinado insumo tenham aumentado durante o período de análise, é possível que a variação em termos de custos de produção ocorra em sentido contrário, indicado neste caso uma redução da quantidade aplicada e utilizada deste insumo no processo produtivo.

Em relação à mão de obra, ocorreu um aumento no preço de 7,7\%. Esta variação é decorrente do reajuste anual no salário dos trabalhadores, contudo a variação no custo foi negativa, pois é resultante do processo de mecanização na agricultura e redução da participação deste grupo nos custos de produção. Este comportamento pode ter ocorrido em função de um menor quadro de funcionários contratados pelos fornecedores, pois, se observada a variação do item Combustível (diesel), ocorreu uma variação por tonelada de 13,38\%, apontando uma possibilidade de maior utilização de maquinário nas propriedades, diminuindo assim a necessidade de um grande quadro de funcionários. 
A Tabela 3 apresenta a variação dos preços dos itens por região, como apresentado na metodologia, cada painel tem uma ponderação em relação a sua produção de cana-deaçúcar e os pesos dos itens de cada painel são ponderados em função dos custos que estes itens representam para os fornecedores.

Tabela 3. Variação dos itens nas mesorregiões

\begin{tabular}{ccccc}
\hline Produto & Catanduva & Piracicaba & Porecatu & Sertãozinho \\
\hline Corretivos & $16,7 \%$ & $19,0 \%$ & $15,1 \%$ & $21,6 \%$ \\
Fertilizantes & $11,9 \%$ & $11,0 \%$ & $12,3 \%$ & $10,4 \%$ \\
Herbicidas & $-0,1 \%$ & $-3,8 \%$ & $2,6 \%$ & $-2,2 \%$ \\
Inseticidas & $-17,0 \%$ & $-9,4 \%$ & $2,9 \%$ & $-9,1 \%$ \\
Lubrificantes & $16,8 \%$ & $19,3 \%$ & $14,3 \%$ & $16,8 \%$ \\
Mão de obra & $7,7 \%$ & $9,8 \%$ & $6,0 \%$ & $6,9 \%$ \\
Mudas & $16,6 \%$ & $11,5 \%$ & $16,5 \%$ & $4,3 \%$ \\
Combustível (Diesel) & $5,3 \%$ & $5,9 \%$ & $4,0 \%$ & $3,0 \%$ \\
\hline
\end{tabular}

Fonte: Dados do projeto

As tabelas contidas nos anexos apresentam alguns indicadores estatísticos da pesquisa de preços de insumos. É possível observar o comportamento dos produtos coletado por região, analisando a variação acumulada, a média, o desvio padrão e o coeficiente de variação. Por exemplo, o item que apresentou uma maior variabilidade no período analisado foram os corretivos, que apontaram um coeficiente de variação de 20,73\%, como é o caso do gesso no painel de Sertãozinho/PR.

\section{Expectativas}

Como expectativas para a safra 2015/2016, que se inicia em abril de 2015, esperase, em um primeiro momento, uma pressão de aumento nos preços de insumos no mercado brasileiro em razão da alta do dólar, já que muitos produtos ou componentes dos produtos são importados, principalmente da classe de fertilizantes. Por outro lado, a queda do preço internacional do barril de petróleo faz com que seus derivados tenham redução nos preços em dólares, ou seja, acredita-se que a redução dos preços internacionais deva amenizar a pressão de alta dos preços internos. Mais que isso, há perspectivas no mercado mundial de desaceleração da demanda por fertilizantes, principalmente em razão da queda de preços das principais commodities agrícolas, podendo também refletir nos preços dos insumos. Até o momento, os patamares de preços se mantiveram por conta do nível de estoques. 
Outro fator que espera-se ter impacto significativo nos preços é o aumento do diesel, que, além de ser utilizado como insumo direto nos maquinários para a produção no campo, ainda deve ser considerado para transporte de outros insumos utilizados, que deverão ter encarecimento do frete.

\section{Referências}

Companhia Nacional De Abastecimento [CONAB]. 2015. Séries Históricas. Disponível em: <http://www.conab.gov.br/>. Acesso em: 18 mar. 2015.

Instituto Brasileiro de Geografia e Estatística [IBGE]. 2015. Sistema IBGE de Recuperação Eletrônica (SIDRA). Disponível em: <http://www.sidra.ibge.gov.br/>. Acesso em: 18 mar. 2015. 


\section{Anexos}

Anexo A. Preços médios, variação acumulada, desvio padrão e coeficiente de variação - de maio de 2014 a janeiro de 2015

\begin{tabular}{|c|c|c|c|c|c|c|c|}
\hline Painel & Item & Subitem & Unidade & Variação Acumulada & Média & Desvio padrão & Coeficiente de Variação \\
\hline & Corretivos & Calcário dolomítico & $\mathrm{R} \$$ / ton & $8,84 \%$ & 97,40 & 9,04 & $9,28 \%$ \\
\hline & Corretivos & Gesso & $\mathrm{R} \$ /$ ton & $24,62 \%$ & 75,70 & 7,13 & $9,43 \%$ \\
\hline & Fertilizantes & $04-20-20$ & $\mathrm{R} \$ /$ ton & $13,29 \%$ & 1182,80 & 71,90 & $6,08 \%$ \\
\hline & Fertilizantes & $28-00-22$ & $\mathrm{R} \$ /$ ton & $10,54 \%$ & 1169,96 & 57,10 & $4,88 \%$ \\
\hline & Herbicidas & Diuron & $\mathrm{R} \$ / \mathrm{Kg}$ & $-10,04 \%$ & 26,12 & 1,05 & $4,03 \%$ \\
\hline & Herbicidas & Glifosato & $\mathrm{R} \$ / \mathrm{l}$ & $7,36 \%$ & 12,60 & 0,40 & $3,15 \%$ \\
\hline \multirow[t]{14}{*}{ Catanduva } & Herbicidas & Plateau & $\mathrm{R} \$ / \mathrm{kg}$ & $-2,09 \%$ & 450,00 & 3,63 & $0,81 \%$ \\
\hline & Herbicidas & Tebutiuron & $\mathrm{R} \$ / \mathrm{l}$ & $4,33 \%$ & 32,80 & 1,03 & $3,14 \%$ \\
\hline & Inseticidas & Regent & $\mathrm{R} \$ / \mathrm{kg}$ & $-16,99 \%$ & 496,92 & 33,39 & $6,72 \%$ \\
\hline & Lubrificantes & Óleo Lubrificante & $\mathrm{R} \$ / \mathrm{l}$ & $16,75 \%$ & 10,44 & 1,09 & $10,47 \%$ \\
\hline & Mudas & Mudas & $\mathrm{R} \$ /$ ton de muda & $16,57 \%$ & 84,16 & 6,82 & $8,10 \%$ \\
\hline & Combustível (Diesel) & Óleo diesel & $\mathrm{R} \$ / \mathrm{I}$ & $5,34 \%$ & 2,17 & 0,05 & $2,35 \%$ \\
\hline & Mão de obra & Cortador de cana (soqueira) & $\mathrm{R} \$$ / mês & $7,71 \%$ & 842,94 & 33,14 & $3,93 \%$ \\
\hline & Corretivos & Calcário dolomítico & $\mathrm{R} \$$ / ton & $8,84 \%$ & 97,40 & 9,04 & $9,28 \%$ \\
\hline & Corretivos & Gesso & $\mathrm{R} \$ /$ ton & $29,11 \%$ & 95,87 & 7,64 & $7,97 \%$ \\
\hline & Fertilizantes & $05-25-25$ & $\mathrm{R} \$ /$ ton & $11,07 \%$ & 1296,67 & 57,84 & $4,46 \%$ \\
\hline & Fertilizantes & $18-00-27$ & $\mathrm{R} \$ /$ ton & $10,18 \%$ & 1190,83 & 58,56 & $4,92 \%$ \\
\hline & Fertilizantes & $20-00-20$ & $\mathrm{R} \$ /$ ton & $11,64 \%$ & 1146,23 & 60,91 & $5,31 \%$ \\
\hline & Herbicidas & Diuron & $\mathrm{R} \$ / \mathrm{Kg}$ & $-5,80 \%$ & 27,03 & 1,02 & $3,77 \%$ \\
\hline & Herbicidas & Glifosato & $\mathrm{R} \$ / \mathrm{l}$ & $7,36 \%$ & 12,60 & 0,40 & $3,15 \%$ \\
\hline \multirow[t]{8}{*}{ Piracicaba } & Herbicidas & Msma & $\mathrm{R} \$ / \mathrm{l}$ & $-5,74 \%$ & 14,17 & 0,50 & $3,54 \%$ \\
\hline & Herbicidas & Tebutiuron & $\mathrm{R} \$ / \mathrm{l}$ & $-11,16 \%$ & 29,23 & 2,45 & $8,38 \%$ \\
\hline & Inseticidas & Carbofurano & $\mathrm{R} \$ / \mathrm{kg}$ & $0,76 \%$ & 28,03 & 0,37 & $1,31 \%$ \\
\hline & Inseticidas & Regent & $\mathrm{R} \$ / \mathrm{kg}$ & $-19,59 \%$ & 556,47 & 64,08 & $11,51 \%$ \\
\hline & Lubrificantes & Óleo Lubrificante & $\mathrm{R} \$ / \mathrm{l}$ & $19,28 \%$ & 9,43 & 0,89 & $9,45 \%$ \\
\hline & Mudas & Mudas & $\mathrm{R} \$ /$ ton de muda & $11,46 \%$ & 82,38 & 4,70 & $5,71 \%$ \\
\hline & Combustível (Diesel) & Óleo diesel & $\mathrm{R} \$ / \mathrm{I}$ & $5,87 \%$ & 2,16 & 0,05 & $2,41 \%$ \\
\hline & Mão de obra & Cortador de cana (soqueira) & $\mathrm{R} \$ /$ mês & $9,76 \%$ & 855,56 & 42,16 & $4,93 \%$ \\
\hline
\end{tabular}


Anexo A. Preços médios, variação acumulada, desvio padrão e coeficiente de variação - de maio de 2014 a janeiro de 2015

\begin{tabular}{|c|c|c|c|c|c|c|c|}
\hline Painel & Item & Subitem & Unidade & Variação Acumulada & Média & Desvio padrão & $\begin{array}{c}\text { Coeficiente de } \\
\text { Variação }\end{array}$ \\
\hline \multirow{14}{*}{ Sertãozinho } & Corretivos & Calcário dolomítico & $\mathrm{R} \$ /$ ton & $8,84 \%$ & 97,40 & 9,04 & $9,28 \%$ \\
\hline & Corretivos & Gesso & $\mathrm{R} \$ /$ ton & $34,39 \%$ & 74,84 & 15,52 & $20,73 \%$ \\
\hline & Fertilizantes & $05-25-25$ & $\mathrm{R} \$ /$ ton & $11,49 \%$ & 1332,62 & 67,97 & $5,10 \%$ \\
\hline & Fertilizantes & $18-00-27$ & $\mathrm{R} \$ /$ ton & $9,36 \%$ & 1175,23 & 49,93 & $4,25 \%$ \\
\hline & Herbicidas & 2,4 D & $\mathrm{R} \$ / \mathrm{l}$ & $3,91 \%$ & 10,96 & 0,16 & $1,47 \%$ \\
\hline & Herbicidas & Diuron & $\mathrm{R} \$ / \mathrm{Kg}$ & $-7,12 \%$ & 25,80 & 0,76 & $2,93 \%$ \\
\hline & Herbicidas & Plateau & $\mathrm{R} \$ / \mathrm{kg}$ & $-3,94 \%$ & 441,85 & 7,16 & $1,62 \%$ \\
\hline & Herbicidas & Tebutiuron & $\mathrm{R} \$ / \mathrm{l}$ & $-1,64 \%$ & 31,42 & 1,08 & $3,43 \%$ \\
\hline & Inseticidas & Carbofurano & $\mathrm{R} \$ / \mathrm{kg}$ & $0,71 \%$ & 28,20 & 0,22 & $0,77 \%$ \\
\hline & Inseticidas & Regent & $\mathrm{R} \$ / \mathrm{kg}$ & $-18,99 \%$ & 494,89 & 35,48 & $7,17 \%$ \\
\hline & Lubrificantes & Óleo Lubrificante & $\mathrm{R} \$ / \mathrm{l}$ & $16,75 \%$ & 10,80 & 1,19 & $11,04 \%$ \\
\hline & Mudas & Mudas & $\mathrm{R} \$ /$ ton de muda & $4,29 \%$ & 79,87 & 1,75 & $2,18 \%$ \\
\hline & Combustível (Diesel) & Óleo diesel & $\mathrm{R} \$ / \mathrm{I}$ & $2,97 \%$ & 2,15 & 0,05 & $2,52 \%$ \\
\hline & Mão de obra & $\begin{array}{c}\text { Cortador de cana } \\
\text { (soqueira) }\end{array}$ & $\mathrm{R} \$$ / mês & $6,91 \%$ & 834,89 & 29,51 & $3,54 \%$ \\
\hline \multirow{12}{*}{ Porecatu } & Corretivos & Calcário dolomítico & $\mathrm{R} \$$ / ton & $8,43 \%$ & 71,83 & 10,73 & $14,94 \%$ \\
\hline & Corretivos & Gesso & $\mathrm{R} \$$ / ton & $21,84 \%$ & 101,79 & 8,66 & $8,51 \%$ \\
\hline & Fertilizantes & $05-30-15$ & $\mathrm{R} \$$ / ton & $9,04 \%$ & 1284,30 & 49,28 & $3,84 \%$ \\
\hline & Fertilizantes & $20-00-20$ & $\mathrm{R} \$ /$ ton & $15,66 \%$ & 1143,31 & 61,01 & $5,34 \%$ \\
\hline & Herbicidas & Diuron & $\mathrm{R} \$ / \mathrm{Kg}$ & $5,81 \%$ & 35,28 & 6,10 & $17,29 \%$ \\
\hline & Herbicidas & Glifosato & $\mathrm{R} \$ / \mathrm{l}$ & $0,94 \%$ & 13,31 & 0,67 & $5,01 \%$ \\
\hline & Herbicidas & Tebutiuron & $\mathrm{R} \$ / \mathrm{l}$ & $0,98 \%$ & 31,67 & 0,13 & $0,39 \%$ \\
\hline & Inseticidas & Regent & $\mathrm{R} \$ / \mathrm{kg}$ & $2,89 \%$ & 809,15 & 8,09 & $1,00 \%$ \\
\hline & Lubrificantes & Óleo Lubrificante & $\mathrm{R} \$ / \mathrm{l}$ & $14,33 \%$ & 8,87 & 0,88 & $9,89 \%$ \\
\hline & Mudas & Mudas & $\mathrm{R} \$ /$ ton de muda & $16,45 \%$ & 84,76 & 7,41 & $8,74 \%$ \\
\hline & Combustível (Diesel) & Óleo diesel & $\mathrm{R} \$ / \mathrm{I}$ & $4,02 \%$ & 2,22 & 0,04 & $1,72 \%$ \\
\hline & Mão de obra & $\begin{array}{l}\text { Cortador de cana } \\
\text { (soqueira) }\end{array}$ & $\mathrm{R} \$$ / mês & $6,00 \%$ & 790,53 & 24,35 & $3,08 \%$ \\
\hline
\end{tabular}


Anexo B. Pesos dos painéis e dos itens que os compõem

\begin{tabular}{|c|c|c|c|c|}
\hline $\begin{array}{c}\text { Painel/UF } \\
\text { (Ponderação) }\end{array}$ & Item & Peso Subgrupo (\%) & Peso Item (\%) & Peso produto e serviço (\%) \\
\hline \multirow{8}{*}{$\begin{array}{l}\text { Catanduva/SP } \\
(41,34 \%)\end{array}$} & Corretivos & $59,31 \%$ & $5,30 \%$ & $2,65 \%$ \\
\hline & Fertilizantes & $59,31 \%$ & $33,65 \%$ & $16,83 \%$ \\
\hline & Herbicidas & $59,31 \%$ & $5,57 \%$ & $1,39 \%$ \\
\hline & Inseticidas & $59,31 \%$ & $1,73 \%$ & $1,73 \%$ \\
\hline & Lubrificantes & $59,31 \%$ & $0,39 \%$ & $0,39 \%$ \\
\hline & Mudas & $59,31 \%$ & $8,74 \%$ & $8,74 \%$ \\
\hline & Combustível (Diesel) & $59,31 \%$ & $3,93 \%$ & $3,93 \%$ \\
\hline & Mão de obra & $40,69 \%$ & $40,69 \%$ & $40,69 \%$ \\
\hline \multirow{8}{*}{$\begin{array}{c}\text { Piracicaba/SP } \\
(30,24 \%)\end{array}$} & Corretivos & $56,59 \%$ & $2,93 \%$ & $1,46 \%$ \\
\hline & Fertilizantes & $56,59 \%$ & $28,06 \%$ & $9,35 \%$ \\
\hline & Herbicidas & $56,59 \%$ & $6,53 \%$ & $1,63 \%$ \\
\hline & Inseticidas & $56,59 \%$ & $2,80 \%$ & $1,40 \%$ \\
\hline & Lubrificantes & $56,59 \%$ & $0,74 \%$ & $0,74 \%$ \\
\hline & Mudas & $56,59 \%$ & $7,41 \%$ & $7,41 \%$ \\
\hline & Combustível (Diesel) & $56,59 \%$ & $7,38 \%$ & $7,38 \%$ \\
\hline & Mão de obra & $44,16 \%$ & $44,16 \%$ & $44,16 \%$ \\
\hline \multirow{8}{*}{$\begin{array}{l}\text { Sertãozinho/SP } \\
\quad(21,25 \%)\end{array}$} & Corretivos & $59,99 \%$ & $3,45 \%$ & $1,73 \%$ \\
\hline & Fertilizantes & $59,99 \%$ & $30,65 \%$ & $15,33 \%$ \\
\hline & Herbicidas & $59,99 \%$ & $7,23 \%$ & $1,81 \%$ \\
\hline & Inseticidas & $59,99 \%$ & $7,57 \%$ & $2,52 \%$ \\
\hline & Lubrificantes & $59,99 \%$ & $0,32 \%$ & $0,32 \%$ \\
\hline & Mudas & $59,99 \%$ & $7,58 \%$ & $7,58 \%$ \\
\hline & Combustível (Diesel) & $59,99 \%$ & $3,19 \%$ & $3,19 \%$ \\
\hline & Mão de obra & $40,01 \%$ & $40,01 \%$ & $40,01 \%$ \\
\hline \multirow{8}{*}{$\begin{array}{l}\text { Porecatu/PR } \\
\quad(7,17 \%)\end{array}$} & Corretivos & $50,99 \%$ & $4,52 \%$ & $2,26 \%$ \\
\hline & Fertilizantes & $50,99 \%$ & $25,09 \%$ & $12,54 \%$ \\
\hline & Herbicidas & $50,99 \%$ & $10,33 \%$ & $3,44 \%$ \\
\hline & Inseticidas & $50,99 \%$ & $0,23 \%$ & $0,23 \%$ \\
\hline & Lubrificantes & $50,99 \%$ & $0,33 \%$ & $0,33 \%$ \\
\hline & Mudas & $50,99 \%$ & $7,20 \%$ & $7,20 \%$ \\
\hline & Combustível (Diesel) & $50,99 \%$ & $3,30 \%$ & $3,30 \%$ \\
\hline & Mão de obra & $49,01 \%$ & $49,01 \%$ & $49,01 \%$ \\
\hline
\end{tabular}

